$\begin{array}{ll}\text { Abstracta Iranica } & \begin{array}{l}\text { Abstracta Iranica } \\ \text { Revue bibliographique pour le domaine irano-aryen }\end{array} \\ & \text { Volume } 25 \mid \mathbf{2 0 0 4} \\ & \text { Comptes rendus des publications de } \mathbf{2 0 0 2}\end{array}$

\title{
Silk Road Art and Archaeology, 8, (2002), 272 p.
}

\author{
Étienne de La Vaissière
}

\section{(2) OpenEdition}

Journals

Édition électronique

URL : http://journals.openedition.org/abstractairanica/4225

DOI : 10.4000/abstractairanica.4225

ISSN : 1961-960X

Éditeur :

CNRS (UMR 7528 Mondes iraniens et indiens), Éditions de l'IFRI

Édition imprimée

Date de publication : 15 mai 2004

ISSN : 0240-8910

\section{Référence électronique}

Étienne de La Vaissière, "Silk Road Art and Archaeology, 8, (2002), 272 p. », Abstracta Iranica [En ligne], Volume 25 | 2004, document 58, mis en ligne le 15 mars 2006, consulté le 25 septembre 2020. URL : http://journals.openedition.org/abstractairanica/4225; DOI : https://doi.org/10.4000/ abstractairanica. 4225

Ce document a été généré automatiquement le 25 septembre 2020.

Tous droits réservés 
Silk Road Art and Archaeology, 8, (2002), 272 p.

Étienne de La Vaissière 
1 Ce numéro de SRAA est une nouvelle fois largement consacré aux études iraniennes et centre-asiatiques :

2 - A. V. Simonenko, "Sarmatian relics of the 'Eastern Wave' in the North Pontic Region ", pp. 1-28, analyse le passage de la période sarmate précoce à la période sarmate moyenne au nord de la mer Noire en reprenant l'ensemble des données disponibles et notamment les caractères locaux ou intrusifs (" eastern wave ») présents sur les sites du $1^{\text {er }}$ et $2^{\mathrm{e}} \mathrm{s}$. de n.è.

3 - E. Errington, "Numismatic evidence for dating the 'Kanișka' reliquary " avec un appendice de H. Falk, «The inscription on the so-called Kanișka casket », pp. 101-120 date le reliquaire du règne d'Huviṣka: il aurait été placé là à l'occasion d'un élargissement du stupa dans lequel il a été retrouvé ; H. Falk propose une lecture de l'inscription.

4 - P. Callieri, "The Bactrian Seal of Khingila», pp. 121-140 et N. Sims-Williams, "The Bactrian inscription on the seal of Khingila », pp. 143-148 traitent tous deux d'un sceau inscrit au nom de Khingila et représentant ce souverain, que l'on placera soit vers 400 soit vers 450 selon le système de datation adopté, le premier en le comparant avec la glyptique kidarite et alxon, et le second en déchiffrant l'inscription «eškiggilo [ ] (r)ōkano xoēo » et en en discutant la paléographie.

5 - M. Alram, «A Rare Hunnish Coin Type », pp. 149-153 discute les 3 spécimens connus d'une des monnaies utilisées par P. Callieri dans l'article ci-dessus et dont l'un porte la légende « ēb(-) » abréviation d'Ephtalite (« èbodalo »).

6 - F. Grenet, E. de la Vaissière, "The Last Days of Panjikent », pp.155-196 éditent, traduisent et commentent les documents politiques du fonds sogdien du Mont Mugh et détaillent la situation politique en Sogdiane en 722. La qualité des informations de Ṭabarī est notamment à souligner. Cartes détaillées du Haut Zérafshan, des opérations en 722 et de la région Samarcande-Pendjikent.

INDEX

Thèmes : 3.1. Est de l'Iran

\section{AUTEURS}

ÉTIENNE DE LA VAISSIÈRE

EPHE - ENS - Paris 